\title{
Analysis of distribution of chlorophyll-a and sea-ice in the Southern Ocean using MODIS data
}

\author{
Chao Song ${ }^{1, a^{*}}$, Chen Zeng ${ }^{2, b}$ and Qian Li ${ }^{1, c}$ \\ ${ }^{1}$ School of Remote Sensing and Information Engineering, Wuhan University, 129 Luoyu Road, \\ Wuhan, 430079, China \\ ${ }^{2}$ State Key Laboratory of Marine Geology, Tongji University, Shanghai, 200092, China \\ songchao@whu.edu.cn,07zengchen@tongji.edu.cn, liqian_rs@whu.edu.cn
}

\begin{abstract}
Keywords: MODIS, chlorophyll-a, the Southern Ocean
Abstract. Chlorophyll-a concentration is an important parameter of the Southern Ocean water environment, and is influenced by factors such as melting sea-ice and so on. This paper validated and justified the applicability of chlorophyll-a and sea-ice extent derived from MODIS data in understanding the spatial-temporal chlorophyll-a distribution in the Southern Ocean. The sea-ice cover reduced evenly between October and January, and the distribution of Chlorophyll-a varies with latitude and the distribution of melting sea-ice.
\end{abstract}

\section{Introduction}

Previous studies show that chlorophyll-a variation in the Southern Ocean play a critical role in modulating climate change and global biogeochemical cycling [1].Focused on the asymmetrically distribution of chlorophyll-a in the Southern Ocean water column, many researchers indicated that phytoplankton blooms are triggered by the interaction between currents and topographic features. Studies also shows that reduced ice cover can favor the formation and growth of phytoplankton [2,3]. Moreover, factors that affect phytoplankton biomass can also include the availability of iron, which increases with melting sea-ice, floating ice packs, and melting glaciers [4,5].

However, studies based on in situ data typically focus on biologically productive marginal ice zones in selective parts of the Southern Ocean. This leaves gaps in our understanding of the spatial and temporal dynamics of chlorophyll distribution across the entire region [6]. Satellite data, providing the greater opportunity for spatial coverage of the Southern Ocean due to the multiple spatial, temporal, and spectral resolutions of satellite imagery [2,3]. Previous studies found there are relationships between chlorophyll-a and other physical processes from ocean color measurements at broad scales by using satellite data [7]. The use of satellite data in ocean process studies of the Southern Ocean has an accuracy of $60 \%$ for the Sea-Viewing Wide Field-of-View Sensor (SeaWiFS) and up to 51\% for Moderate Resolution Imaging Spectrometer (MODIS) [8].To seek a better understanding of chlorophyll-a distribution, satellite remote sensing to continuously monitor chlorophyll-a concentration at large scales is needed [9].

In this study, we assess MODIS data set to explore the impact of sea-ice concentrations on the chlorophyll-a distribution patterns by geographic region. Examining latitudinal zones could help in understanding regional phytoplankton dynamics, as symmetrical distributions of phytoplankton, zooplankton and biotopes are caused by similar macro circulation patterns at different latitudinal zones. Validation experiments between the MODIS derived chlorophyll-a and in situ data as well as between sea-ice cover and MODIS ice flag data was carried out to validate and justify the applicability of satellite imagery from MODIS for use in understanding the spatial-temporal chlorophyll-a distribution in the Southern Ocean.

\section{Materials and methodology}

Study Area. The Southern Ocean consists of the southern portions of the Atlantic, Indian, and Pacific Oceans, and covers the region from the South Pole to the $60^{\circ} \mathrm{S}$ latitude (Fig.1). As the fourth largest 
ocean in the world, the Southern Ocean has sea surface temperatures ranging from $10^{\circ} \mathrm{C}$ to $-2^{\circ} \mathrm{C}$. The temperature contrast between ice and open ocean water in the Southern Ocean creates strong winds which travel eastward and are responsible for generating the Antarctic Circumpolar Current.

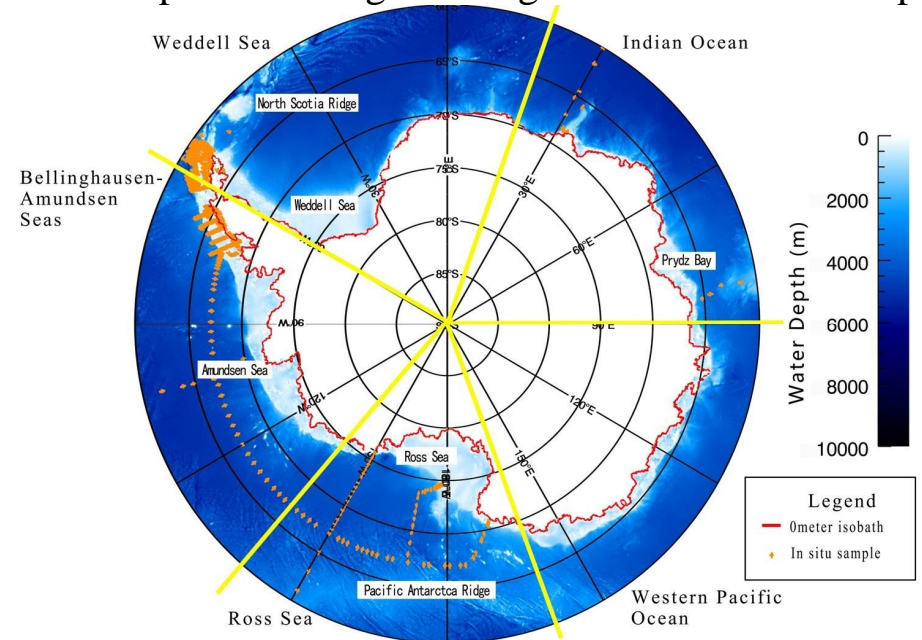

Fig.1 Study area: the Southern Ocean and in situ sample distribution (orange points).

Data Acquisition and Preparation. In situ, high performance liquid chromatography (HPLC) samples between October 2002 and March 2012, were compiled from the SeaBASS bio-optical data archive and the Palmer Long Term Ecological Research (LTER) program.

We obtained MODIS-derived daily level3 standard gridded images of surface chlorophyll-a concentration $(4.25 \mathrm{~km} \times 4.25 \mathrm{~km})$ during the period October 2002 to March 2012 from the Ocean Color Website (http://oceancolor.gsfc.nasa.gov). Since half of the year in the Southern Ocean is dark due to low solar elevation, the available ocean color data covers only from October to March. The data was averaged across months to fully take into account the accumulation of algal biomass and data loss from quality control flags [6]. Several attributes, including chlorophyll-a, sea-ice cover, and QA/QC flags were computed for latitudinal zones $60-65^{\circ} \mathrm{S}, 65-70^{\circ} \mathrm{S}$ and $>70^{\circ} \mathrm{S}$ for each month.

MODIS flag data is typically used to mask atmospheric interference, poor sensor performance or physical coverage. In high latitude areas the sea-ice flag can be used to assess sea-ice extent and coverage. MODIS flagged data were analyzed against sea-ice concentration $(25 \mathrm{~km} \times 25 \mathrm{~km})$ which was downloaded from National Snow \& Ice Data Center (NSIDC, http://nsidc.org/data/docs/daac/nsi dc0051_gsfc_seaice.gd.html).

\section{Results and discussion}

Data Validation. In situ data and MODIS data probability distributions by latitudinal regions (Fig.2) illustrated good agreement especially in the $65^{\circ}-70^{\circ}$ and $>70^{\circ}$ latitudinal zones (Fig.2b and c). Although their peaks reached different values, the two data sets showed similar distributions. Satellite data, distributed evenly around the study area.
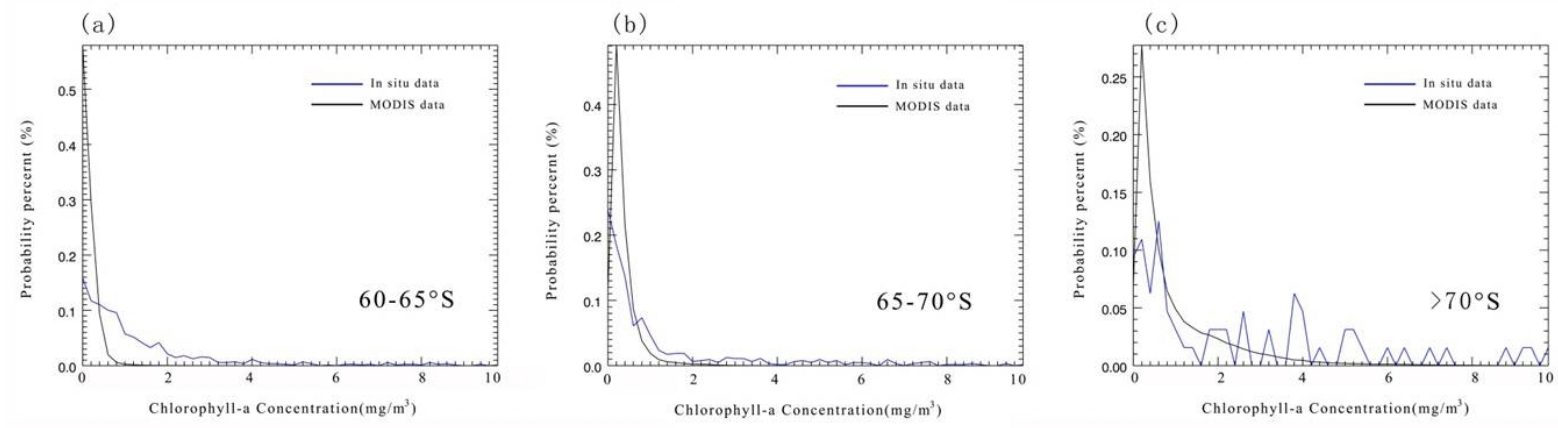

Fig. 2 Chlorophyll-a concentration probability distribution in $60^{\circ}-65^{\circ}, 65^{\circ}-70^{\circ}$ and $>70^{\circ}$ latitudinal zones. 
The sea-ice concentration of different level $(15 \%, 20 \%, 30 \%, 40 \%$ and $50 \%)$ was matched up with the MODIS flag data to examine the extent of sea-ice, and the $50 \%$ concentration MODIS product provided a better visual match. The white line in Fig.3 showed that a sea-ice concentration at $15 \%$ had a much greater extent than the sea-ice area flagged in the MODIS data set. Red lines (sea-ice concentration of 50\%) matched the MODIS flag data best with approximately $109(0.01 \%)$ pixels from the 50\% sea-ice concentration coverage data falling outside the NSIDC data set. Of the monthly sea-ice coverage, 43 in November $(0.004 \%), 214$ (0.02\%) in December, 323 in January (0.03\%), 71 in February $(0.007 \%), 7$ in March $(0.0007 \%)$ were flagged erroneously as sea-ice coverage when compared to the NSIDC data set.

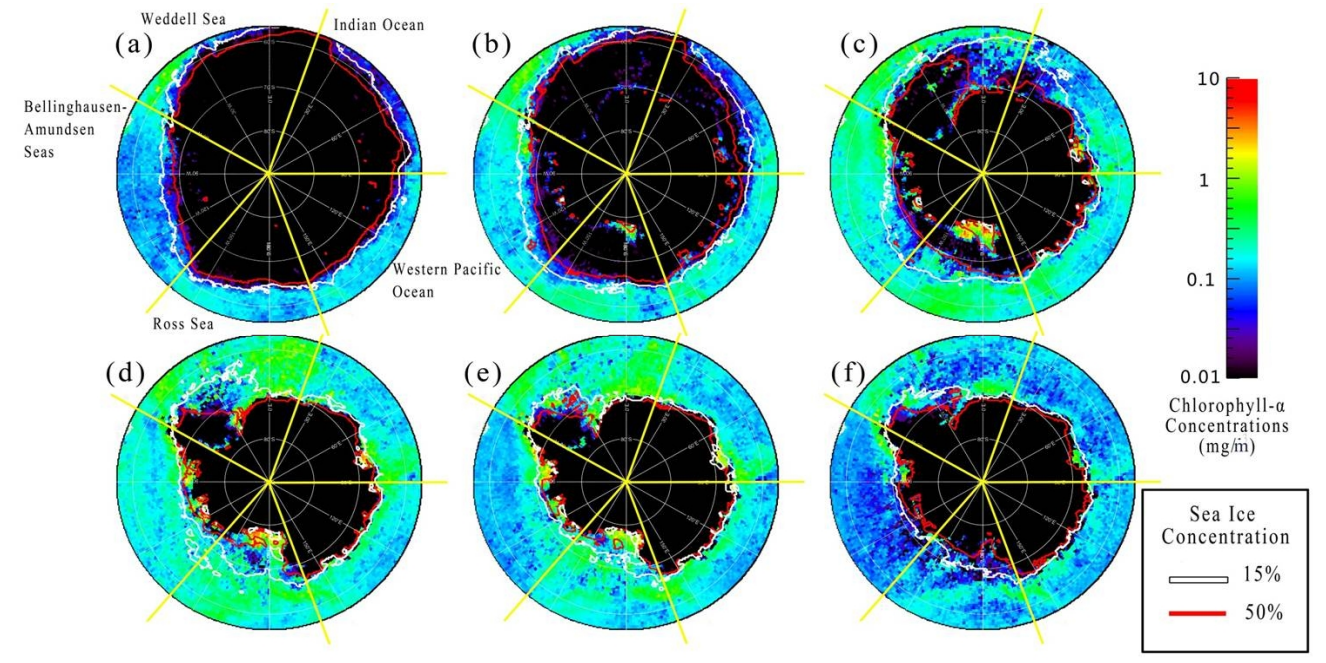

Fig 3. MODIS flag data vs sea-ice concentration (a-f. October to March, yellow lines describe longitudinal classification zones).

Sea-ice and chlorophyll-a distribution comparison. The rate of flag data was calculated to analyze the influence of high sea-ice concentration $(>50 \%)$ on chlorophyll-a distribution (Fig.4). The region $>70^{\circ} \mathrm{S}$ had the highest rate at about $60 \%$ or more. The values were mainly lower than $12 \%$ in $65-70^{\circ} \mathrm{S}$, and were only $0.53-8.34 \%$ in $60-65^{\circ} \mathrm{S}$. A great magnitude in difference of the flag rate implied that there could be a large variation of available chlorophyll-a data across latitudinal zones.

Flag rate (\%)

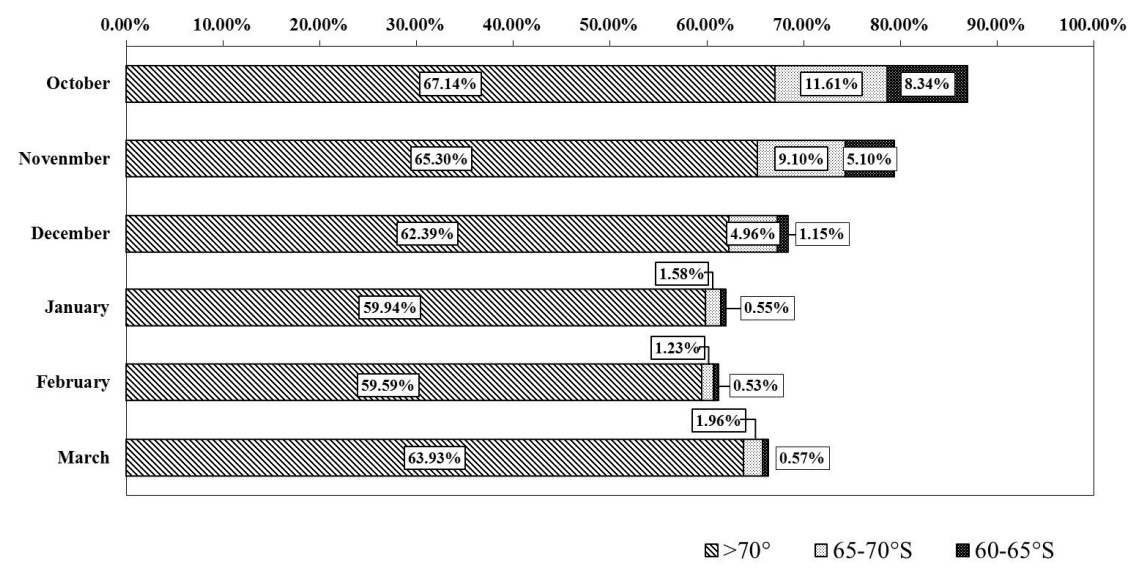

Fig.4 Rate of flag data in latitudinal zones over October to March.

Seasonal variation in sea-ice cover appeared to be similar in all three latitudinal zones (Fig.4), with a reduction occurring from October to February. The sea-ice cover reduced evenly between October and January, and February was the month with the lowest sea-ice cover. In March, sea-ice cover increased dramatically especially in areas $>70^{\circ} \mathrm{S}$. Meanwhile, sea-ice cover in the $65-70^{\circ} \mathrm{S}$ and $60-65^{\circ} \mathrm{S}$ areas was relatively small, indicating the variable growth and decay of sea-ice at different latitudinal layers in March. 
Distribution of chlorophyll-a concentration in Southern Ocean for six months was shown in Fig.3. Chlorophyll-a concentration in the Southern Ocean increased from October to January, decreased through March. Phytoplankton biomass responds positively to solar elevation, a critical limitation for phytoplankton growth [10]. Increasing solar irradiance leads to a warming atmospheric temperature and results in severe sea-ice melting. This provides more space and nutrients for phytoplankton growth. In addition, melting sea-ice generates fresh water for stratification, which plays an important role in facilitating phytoplankton accumulation and a stable living environment.

Though the sea-ice coverage appeared to be smallest in February, the peak of chlorophyll-a concentration occurred in January. Sufficient ice free areas in January guarantee adequate space for phytoplankton growth, so the seasonal declines in blooms that begin in February are likely due to the shortage of nutrients, and the lack of optimal conditions such as vertical mixing induced by winds or decreased irradiance.

\section{Conclusions}

This paper examined the distribution of chlorophyll-a derived from MODIS data in the Southern Ocean, which varies with latitude, and the distribution of melting sea-ice. MODIS-derived chlorophyll-a resulted well correlations with in situ data. A higher correlation occurred between MODIS flag data and 50\% sea-ice concentration line, possibly due to light penetration through the loose ice pack. Further research is required to verify this finding.

Since 2002, MODIS has been providing a synoptic view of chlorophyll-a distribution in Southern Ocean. This research improves the accuracy of identifying chlorophyll-a distribution here and contributes to a better understanding of the spatial and temporal dynamics of phytoplankton.

\section{References}

[1] Wang, S., Moore, J. K., Variability of primary production and air-sea CO2 flux in the Southern Ocean, Global Biogeochemical Cycles. 26(2012).

[2] Arrigo, K. R., van Dijken, G. L. Phytoplankton dynamics within 37 Antarctic coastal polynya systems, Journal of Geophysical Research: Oceans. 108(2003), 3271.

[3] Arrigo, K. R., van Dijken, G., Long, M, Coastal Southern Ocean: a strong anthropogenic CO2 sink, Geophysical Research Letters. 35(2008).

[4] Boyd, P. W., Jickells, T., Law, C. S., etc, Mesoscale iron enrichment experiments 1993-2005: Synthesis and future directions, Science. 315(2007), 612-617.

[5] Raiswell, R., Tranter, M., Benning, L. G., etc, Contributions from glacially derived sediment to the global iron (oxyhydr) oxide cycle: implications for iron delivery to the oceans, Geochimica et Cosmochimica Acta. 70(2006), 2765-2780.

[6] Moore, J. K., Abbott, M. R., Phytoplankton chlorophyll distributions and primary production in the Southern Ocean, Journal of Geophysical Research: Oceans. 105(2000), 28709-28722.

[7] Arrigo, K. R., van Dijken, G. L., Bushinsky, S. Primary production in the Southern Ocean, 1997-2006, Journal of Geophysical Research: Oceans. 113(2008).

[8] Johnson, R., Strutton, P. G., Wright, S. W., etc, Three improved Satellite Chlorophyll-algorithms for the Southern Ocean, Journal Geophysics Research Oceans. 118(2013), 3694-3703.

[9] Moore, J. K.,Abbott, M. R., Surface chlorophyll concentrations in relation to the Antarctic Polar Front: seasonal and spatial patterns from satellite observations, J of Marine Systems. 37(2002), 69-86.

[10] De Baar, H. J., Boyd, etc, Synthesis of iron fertilization experiments: from the iron age in the age of enlightenment, Journal of Geophysical Research: Oceans. 110(2005). 